\title{
TRANSFORMASI KEDAI TUAK SEBAGAI SARANA PENGINJILAN GEREJA
}

\author{
Riris Johanna Siagian ${ }^{1}$, Jojor Silalahi ${ }^{2}$, Ratna Saragih $^{3}$ \\ Sekolah Tinggi Theologia HKBP Pematangsiantar ${ }^{1}$ \\ Universitas HKBP Nommensen Medan ${ }^{2}$, Institut Agama Kristen Negeri Tarutung ${ }^{3}$ \\ ririsjohannasiagian@stthkbp.ac.id
}

\begin{abstract}
This writing tries to analyze the influence of kedai tuak toward the presence of congregation members, especially males in church. It begins with a study of the concrete reality of the church dan how the common response of the father according to it. And how the church does evaluation and reflection of the church, by doing persuasive action for serving the laity, not by giving a negative stigma. This research is qualitative with Sociology of Religion perspective. The expectation, by social analyze so the transformation for changing of preaching method will be get.
\end{abstract}

Keywords: Church, Batak, Preaching, Tuak

\begin{abstract}
Abstrak. Tulisan ini berupaya menggali pengaruh kedai tuak terhadap kehadiran kaum bapak di dalam gereja, adakah faktor-faktor yang ada itu saling terkait atau tidak. Dimulai dengan pemahaman jemaat tentang realitas konkrit atas kehidupan bergereja dan bagaimana penyelenggara gereja menyikapinya dan terbuka melakukan evaluasi dan refleksi atas kehidupan bergereja, kemudian membangun cara-cara yang persuasif untuk merangkul kaum bapak, bukan malah memberi stigma negatif. Penelitian ini bersifat kualitatif dengan pendekatan Sosiologi Agama dan diharapkan transformasi perubahan metode penginjilan dapat dicapai.
\end{abstract}

Kata Kunci: Gereja, Batak, Penginjilan, Tuak (Nira)

\section{PENDAHULUAN}

Gereja yang bertumbuh merupakan gereja yang senantiasa terbuka dan jujur untuk melakukan evaluasi dan refleksi atas berbagai pemahaman teologis baik di bidang pengajaran maupun pemberitaan Injil serta bagaimana implementasi program di tengah-tengah pelayanan gereja. Cara berfikir seperti itu diperlukan untuk mengukur sejauhmana pengajaran tentang Injil dapat dirasakan sebagai kabar sukacita dan terlihat nyata dalam seluruh pelayanan gereja di tingkat aksi. (Holland dan Henriot 2013). 
Perlu disadari pula, secara teologis manusia terbatas dalam memahami kehendak Tuhan dan karenanya juga terbatas dalam implementasi. Hal ini tidak hanya dialami jemaat tetapi juga oleh pelayan di tengah-tengah gereja. Untuk itu sangat dibutuhkan kehadiran Roh Kudus untuk menopang dan mengarahkan pelayanan ke arah yang benar dan membentuk perilaku moral ke arah yang positif. (Wulanata 2018).

Untuk waktu yang lama, salah satu pergumulan dan tantangan utama yang dihadapi hampir di seluruh Huria Kristen Batak Protestan (HKBP), terkait dengan minimnya kehadiran dan partisipasi kaum bapak dalam seluruh pelayanan gereja. Hal itu diduga dipicu faktor adanya "kedai tuak" yang berdiri di sekitar gereja. Pertanyaannya, adakah hubungan langsung dari keduanya? Apakah kehadiran kedai tuak menjadi penyebab utama rendahnya kehadiran kaum bapak, atau kedai tuak hanya sebagai simbol pelengkap penderita dari kondisi rill kehidupan bergereja itu sendiri?

\section{METODE PENELITIAN}

Metode penelitian ini bersifat kualitatif dan tidak mensyaratkan jumlah responden yang banyak, tetapi sejauhmana pertanyaan-pertanyaan yang diajukan memeroleh jawaban yang mendalam dan memuaskan serta memenuhi data untuk kebutuhan penulisan. Pencarian data dilakukan dengan metode FGD (Focus Group Discussion) dilakukan terhadap delapan kelompok kategorial bapak yang ada di beberapa gereja, yakni: HKBP Pematangsiantar, Mannen Anugerah Pematangsiantar, HKBP Bah Sampuran, HKBP Perdagangan, HKBP Martoba 
Pematangsiantar, HKBP Parapat, HKBP Tigaras, HKBP Bah Jambi. Keseluruhan gereja itu berada di wilayah Distrik V Sumatera Timur, sebagai satu distrik terbesar kedua dalam seluruh pelayanan HKBP, sekaligus ditetapkan sebagai populasi penelitian, karena dipahami memiliki implikasi besar terhadap seluruh pelayanan gereja di HKBP.

Dalam proses penelitian FGD atau Kelompok Diskusi Terarah ini, peneliti mendatangi setiap gereja yang menjadi tempat penelitian. Setelah berkoordinasi dengan pengurus gereja setempat, peneliti melakukan diskusi dengan 15-25 orang kaum bapak yang ditetapkan sebagai sampel dari gereja yang diteliti. Sebagaimana sifat data penelitian kualitatif, umumnya memuat konsep-konsep yang rumit, maka beberapa konsep itu tetap dapat diukur melalui penggunaan cara yang tepat, yakni indeks dan skala. Oleh karena itu, setelah melakukan Diskusi Kelompok Terfokus, selanjutnya hasil diskusi dituangkan ke dalam daftar pertanyaan beserta pilihan jawaban dalam bentuk a,b,c yang terangkum dalam kuesioner. Penggunaan kedua metode dengan cara mix, kualitatif dan kuantitatif seperti ini biasa dilakukan untuk mendapatkan hasil yang memadai. (Artana 2015).

Metode Kelompok Diskusi Terfokus dipilih karena waktu yang dibutuhkan untuk melakukan penelitian dapat diukur, mensyaratkan interaksi antara peneliti dan responden terkait pertanyaan-pertanyaan yang diajukan, dan mendalam serta, pokok-pokok pikiran yang berkembang di seputar isu dapat segera ditangkap. (Afiyanti 2008). 
Selanjutnya, kuesioner tersebut dibagikan secara acak kepada 1.600 orang responden. Hasil kuesioner dideskripsikan secara kuantitatif beserta data hasil wawancara, lalu dianalisa dan disajikan dalam bentuk tabel sederhana, sebagaian lagi digunakan sebagai bagian dari penulisan. Oleh karena penulis terlihat dalam beberapa kegiatan penelitian di seputar gereja, maka penelitian ini merupakan kelanjutan dari penelitian sebelumnya. Hasil itulah yang dipresentasikan dalam hasil penelitian ini.

\section{HASIL PENELITIAN}

Diskusi dimulai dengan pertanyaan penelitian tentang: apa yang terfikirkan oleh kaum bapak ketika mendengar sebuah kata, 'gereja.' Dari sejumlah jawaban yang disampaikan oleh responden yang dirangkum, kaum bapak mengatakan bahwa gereja adalah: persekutuan Roh Kudus, tempat mencari kebenaran, penuh kasih, bersikap adil, ramah tamah, merangkul, transparan dalam keuangan.

Diperoleh informasi, realitas kehadiran dan partisipasi kaum bapak dalam keseluruhan pelayanan gereja dirasakan sangat minim bila dibandingkan dengan jumlah kaum bapak dalam satu gereja. Kehadiran kaum bapak di dalam gereja setiap minggu rata-rata hanya sekitar $48 \%$. Sementara itu sebanyak $35 \%$ mengakui kehadirannya dalam gereja hanya 1 x 1 bulan, sedangkan $17 \%$ lainnya mengaku hanya hadir 1 x 1 tahun, dan biasanya terutama saat suasana natal dan tahun baru. 
Tabel 1. Kehadiran Dalam Ibadah

\begin{tabular}{|c|c|c|c|c|}
\hline \multirow[t]{2}{*}{ No } & \multirow[t]{2}{*}{ Pertanyaan Penelitian } & \multicolumn{3}{|c|}{$\mathrm{N}=1600(100 \%)$} \\
\hline & & A & B & $\mathrm{C}$ \\
\hline 1 & $\begin{array}{l}\text { Kehadiran dalam gereja: } \\
\text { a. } 1 \text { x } 1 \text { Minggu } \\
\text { b. } 1 \text { x } 1 \text { bulan } \\
\text { c. } 1 \text { x } 1 \text { tahun (natal dan tahun } \\
\text { baru) }\end{array}$ & $\begin{array}{c}772 \\
(48 \%)\end{array}$ & $\begin{array}{l}524 \\
(35 \\
\%)\end{array}$ & $\begin{array}{c}254 \\
(16 \%)\end{array}$ \\
\hline & Total & & & $100 \%$ \\
\hline
\end{tabular}

Ket: A, B,C merupakan pilihan jawaban yang menunjuk pada kehadiran kaum Bapak dalam minggu, bulan, tahun.

Dengan demikian, lebih dari 50\% kaum bapak tidak hadir dalam seluruh pelayanan gerejawi, yang umumnya berlangsung dalam lingkungan gereja. Pertanyaannya, di manakah kaum bapak selama pelayanan gereja berlangsung? Jawaban yang paling umum diperoleh kebanyakan kaum bapak menyibukkan dirinya sendiri. Ironisnya, fakta menunjukkan bahwa kedai tuak berdiri hampir di setiap sudut gereja, dan kaum bapak lebih banyak berkunjung ke kedai tuak dari pada ke gereja. Alasannya sederhana, di tempat itu para pengunjung dapat berbicara apa saja, dan pasti selalu ada yang mendengar dan memberi respons. Ketika ditanyakan mengapa demikian? Jawaban spontan yang terucap, "gereja tidak menarik."

Kenyataan itu berbanding terbalik dengan pemahaman ideal jemaat di mana gereja diharapkan dapat menjadi wadah yang menolong jemaat semakin dekat pada Tuhan. Harapan itu begitu besar mencapai $90 \%$. 
Tabel 2. Harapan Jemaat Akan Fungsi Gereja

\begin{tabular}{|c|c|c|c|c|}
\hline \multirow[t]{2}{*}{ No } & \multirow[t]{2}{*}{ Pertanyaan Penelitian } & \multicolumn{3}{|c|}{$\mathrm{N}=1600(100 \%)$} \\
\hline & & A & B & $\mathrm{C}$ \\
\hline 1 & $\begin{array}{l}\text { Ketenangan dalam gereja diperlukan: } \\
\text { a. Membawa jemaat dekat pada Tuhan } \\
\text { b. Biasa saja } \\
\text { c. Tidak tahu }\end{array}$ & $\begin{array}{c}1432 \\
(90 \%)\end{array}$ & $\begin{array}{c}150 \\
(9 \%)\end{array}$ & $\begin{array}{c}21 \\
(1 \%)\end{array}$ \\
\hline & Total & & & $100 \%$ \\
\hline
\end{tabular}

Ket: Pilihan A,B,dan C beserta angka di bawahnya menunjuk pada fungsi gereja menurut jemaat.

Kecenderungan para pelayan gereja bersikap kurang ramah menyambut kehadiran jemaat, bertindak memilih-milih jemaat yang kaya atau orang-orang yang berpengaruh saja, dianggap terasa sangat mengganggu spiritualitas jemaat. Khotbah, semula sangat diharapkan menopang pergumulan jemaat, juga dirasa tidak memadai, kadang jemaat sangat terganggu dengan hal-hal teknis. Sebanyak $52 \%$ jemaat mengakui keteduhan dalam ibadah sangat penting untuk memerlihatkan penghayatan lebih kuat akan eksistensi Tuhan dalam hidup manusia.

Kebutuhan akan suasana bergereja yang kondusif, penuh kasih, para pelayan diharapkan mengenal jemaatnya dengan baik. Hal itu dikarenakan umumnya jemaat yang datang ke gereja membawa suasana hatinya masingmasing, entah gembira, berkecamuk atau susah, dan lain-lain. Suasana hati itu sendiri sedikit banyak tergambar pada raut wajah.

Dijelaskan juga, gereja berupaya membuat program parheheon ama, semacam acara untuk membangkitkan kaum bapak (KKR). Acara itu biasa diisi 
dengan seminar, pertandingan olah raga bola volley, badminton, catur, dan lain sebagainya. Memang ketika acara itu berlangsung kaum bapak banyak yang datang dan terlibat dalam berbagai kegiatan. Mungkin karena ada beberapa perlombaan di mana kehadiran kaum bapak membawakan masing-masing wikj/sektor, maka kehadiran mereka cukup ramai. Namun setelah itu, kehadiran bapak kembali sunyi. Hanya terutama ketika menjelang suasana natal dan tahun baru, jumlah kaum bapak bisa mencapai dua kali lipat dari jumlah biasa. Umumnya, itu pun karena banyak anak rantau yang pulang kampung.

Menurut responden kehidupan peribadahan dan pelayanan gerejawi sering terganggu karena berbagai problem yang terkait dengan perilaku, angkanya mencapai $55 \%$. Kenyataan ini membuat gereja secara moral tidak dapat berdiri tegak. Beberapa isu moral yang mencuat ke permukaan tetap merupakan kendala utama, terutama bila itu dilakukan para pelayan gereja.

Tabel 3. Gereja Terganggu Karena Persoalan Perilaku

\begin{tabular}{|c|l|c|c|c|}
\hline No & \multicolumn{1}{|c|}{ Pertanyaan Penelitian } & \multicolumn{3}{c|}{$\mathrm{N}=1600(100 \%)$} \\
\cline { 3 - 5 } & \multicolumn{1}{|c|}{$\mathrm{A}$} & $\mathrm{B}$ & $\mathrm{C}$ \\
\hline 1 & $\begin{array}{l}\text { Gereja sering terganggu karena persoalan } \\
\text { perilaku: } \\
\text { a. Ya } \\
\text { b. Biasa saja } \\
\end{array}$ & 876 & 463 & 240 \\
& c. Tidak tahu & $(55 \%)$ & $(29 \%)$ & $(15 \%)$ \\
\hline & \multicolumn{1}{|c|}{ Total } & & & \\
\hline
\end{tabular}

Ket: Huruf dan angka yang terdapat pada opsi A, B C menunjuk pada jumlah jemaat yang menganggap gereja terganggu oleh persoalan perilaku. 
Keterbatasan para pelayan gereja menampilkan suasana yang kondusif dan nyaman dalam kehidupan bergereja, menjadikan jemaat merindukan sosok pelayan yang berkarakter (marsahala), mengayomi, teladan, dapat dipercaya. Tampaknya ini yang makin sulit terlihat dalam diri pelayan sekarang. Berbagai konflik dalam gereja yang dipicu berbagai hal, sangat diharapkan tidak sampai berkepanjangan, karena bisa membuat sebagian jemaat merasa gerah dan mengambil jarak dari kehidupan bergereja.

Tabel 4. Profil Pemimpin Gereja Yang Diharapkan

\begin{tabular}{|c|l|c|c|c|}
\hline No & \multicolumn{1}{|c|}{ Pertanyaan Penelitian } & \multicolumn{3}{|c|}{$\mathrm{N}=1600(100 \%)$} \\
\cline { 3 - 5 } & & $\mathrm{A}$ & $\mathrm{B}$ & $\mathrm{C}$ \\
\hline 1 & $\begin{array}{l}\text { Pemimpin gereja harus bersikap: } \\
\text { a. Mengayomi (marorot) }\end{array}$ & 657 & 747 & 203 \\
& $\begin{array}{l}\text { b. Teladan (sitiruon) } \\
\text { c. Dapat dipercaya (haposan) }\end{array}$ & & & \\
\hline & \multicolumn{1}{|c|}{ Total } & & & $100 \%$ \\
\hline
\end{tabular}

Ket. Opsi A, B, C dan angka masing-masing menunjuk pada profil pelayan yang sangat diharapkan bisa ditampilkan.

Dari penelitian yang dilakukan jemaat sangat mengharapkan para pejabat gereja dapat menampilkan karakter yang baik dan unggul yang menjadi ciri-ciri kepribadiannya, yakni: mengayomi (marorot), keteladanan (sitiruon), dapat dipercaya (haposan). Ketiga pilihan di atas, terutama point a dan b memerlihatkan bahwa hal itu sangat diharapkan terwujud dalam diri pelayan. Ini merupakan tantangan gereja. 


\section{PEMBAHASAN}

Gereja merupakan satu institusi keagamaan yang bersifat rohani, yang diberi mandat oleh Tuhan untuk menyelenggarakan berbagai kegiatan rohani. Lembaga ini diyakini kredibel untuk berbicara tentang kasih, kebaikan, kesetiaan, kebenaran, keadilan, perdamaian dan hal-hal lain yang terkait dengan moral. Para pelayan gereja dihormati sebagai orang-orang yang memiliki wibawa rohani, berkarakter mengayomi (marorot), teladan (sitiruon), dapat dipercaya (haposan). Kepemimpinan pelayan yang berkarakter demikian akan menopang dan menegaskan gereja untuk berdiri tegak sebagai garda terdepan dalam berbicara dan bertindak dalam apa yang diimani, sebagai pelayan Tuhan. (Siagian 2019).

Faktor kepemimpinan yang baik dan kuat di dalam gereja sangat dibutuhkan untuk merangkul semua potensi jemaat dan membuat organisasi gereja berjalan dengan baik dalam persekutuan, kesaksian dan pelayanannya. Oleh karena itu kepemimpinan gereja harus berjalan sesuai dengan panggilan dan tahbisan teologisnya, dengan penuh kasih, sukarela dan sifat melayani yang tulus, sebagaimana tugas untuk Tuhan, bukan untuk manusia apalagi untuk diri sendiri. (Borrong 2019).

Faktanya, pemahaman teologis sedemikian sering teredam oleh hal-hal yang sosiologis. Kenyataan ini menjadi mudah dimengerti ketika sejumlah anggota jemaat mengakui motivasinya datang ke gereja, antara lain; di samping untuk mengucap syukur juga untuk bertemu dengan teman satu arisan, satu punguan marga (kelompok dari satu garis marga seketurunan). Entah sejak 
kapan, belakangan ini di dalam lingkungan gereja selalu diupayakan supaya ada sopo (gedung pertemuan). Biasanya memang, ritual-ritual adat Batak membutuhkan waktu lebih banyak dari pada acara ibadah di dalam gereja sendiri, seperti resepsi pernikahan, adat kematian, perayaan ulang tahun, dan lain sebagainya. Terutama ini dibutuhkan bagi jemaat yang rumahnya terbatas menampung orang, dan juga tidak punya halaman.

Secara teoritis hal ini pun memiliki pembenaran bila dihubungkan dengan pandangan, ketika berlangsung interaksi teologis, maka berlangsung pula interaksi sosiologis. (Durkhaim 1957). Menjadi soal, ketika kemudian fungsi sopo lebih dominan dari fungsi gereja itu sendiri. Di beberapa tempat malah bangunan sopo lebih menjorok ke depan dan lebih besar dari bangunan gereja itu sendiri. Bagaimanapun, kondisi seperti ini kurang nyaman dalam pandangan mata. Dapat terjadi interaksi teologis menjadi terhisap pada interaksi sosiologis. Inilah mengapa kenyataan kehadiran gereja secara sosiologis perlu ditata agar kehadiran Roh Kudus tetap dapat dirasakan dalam kehidupan gereja secara holistik.

Tentang realitas umum yang terjadi dalam pelayanan gereja, biasanya kaum ibu lebih terbuka menerima keadaan. Berbeda dengan kaum bapak, yang biasanya lebih jernih dan peka memandang situasi yang ada. Ketidaksiapan menerima realitas hidup bergereja, di mana kehadiran Roh Kudus, bagi sebagian besar jemaat hampir tidak dirasakan, dan terutama dialami kaum bapak. Ditambah pelayan dianggap kurang kuat dalam hal karakter, otoritas kuasa cenderung digunakan untuk bertindak sebagai tuan, dan mengikuti keinginan daging, serta abai terhadap kehadiran roh. (Ndelo 2013). 
Bagaimanapun, kondisi ini menimbulkan sikap gerah dan tidak nyaman, komunikasi juga menjadi tidak efektif, buntu. Hal ini mendorong berbagai aspek dalam peribadahan disikapi lebih kritis, dan tidak lagi dengan mudah diterima dengan iman sebagai bagian dari ibadah yang kudus. Kondisi ini agak berbeda dengan pengalaman kaum bapak pada masa-masa awal kekristenan dan terus berlangsung hingga tahun 1970-an, di mana kehadiran/partisipasi kaum bapak sangat terasa dalam kehidupan bergereja. Para pelayan gereja berupaya membangun komunikasi yang efektif dalam seluruh pelayanan gereja, sehingga warga jemaat dapat memahami dengan baik gagasan dan program yang sedang dikembangkan di tengah-tengah gereja, dan mendorong jemaat pro aktif. (Siagian 2020).

Pertanyaannya, apa yang salah dengan gereja? Jawaban terhadap ini dapat dicermati dari beberapa sudut. Pertama: melalui penelitian ini, muaranya seputar gereja dan karakter pelayan. Melalui penelitian lain, terungkap khotbah tidak menarik, managemen keuangan tidak transparan, aturan kaku, turut pemicu membuat gereja tidak menarik. Bila hal itu dibenahi akan berkontribusi kuat dalam memotivasi dan memelihara hidup keimanan jemaat. (Siagian 2020). Terhadap ini, para pelayan gereja harus bekerja keras untuk terlebih dahulu membenahi kehidupan gereja dari dalam, agar gereja bisa bergerak lebih lincah untuk memberitakan Injil.

Kedua, motivasi jemaat. Tentu saja pernyataan jemaat itu mengundang banyak tanya, antara lain di manakah kaum bapak berkumpul ketika mereka tidak masuk kerja. Jawaban yang dominan terhadap itu, satu saja, kedai tuak. 
Berdasarkan penelitian, hampir di setiap tempat, di mana gereja ada, maka di sekitar itu selalu ada kedai tuak. Dapat dimengerti, karena di sekitar itu juga terdapat orang Batak yang sekaligus menjadi warga jemaat dari kategorial bapak.

Faktanya, tuak sulit lepas dari kehidupan orang Batak. Kemudian tuak dan kedai tuak menjadi faktor yang dipersalahkan. Memang, kehadiran kedai tuak, tidak mudah dikesampingkan. Para pelayan gereja pun tidak bisa menutup mata terhadap kehadiran kedai tuak, karena tempat itu tetap diminati oleh kaum bapak. Menurut kaum bapak, di beberapa tempat dilakukan juga himbauan supaya kedai tuak tidak buka hari Minggu, sehingga kaum bapak bisa datang ke gereja. Ketika beberapa pemilik kedai tuak berupaya mengikuti himbauan itu, nyatanya kehadiran kaum bapak di dalam gereja juga tidak bertambah. Penelitian lebih jauh terhadap hal ini diperlukan untuk memahami lebih dalam realitas yang ada.

Asumsi yang menguat, ramainya kedai tuak, selain karena diminati kaum bapak, juga karena ketidakpuasan dan rendahnya rasa nyaman dalam kehidupan bergereja, yang dipertontonkan oleh kaum bapak, dan sekaligus menempatkan kedai tuak sebagai unsur pelengkap penderita. Tetapi oleh pihak gereja, kedai tuak menjadi dikebiri dari eksistensinya sebagaimana ia ada. Orang-orang yang minum tuak di tempat itu pun jadinya dipandang dengan nada miring dan negatif. Tuak dan kedai tuak telah jadi kambing hitam.

Ketiga, evaluasi program yang berkesinambungan. Berdasarkan penuturan kaum bapak, awal mereka membentuk kelompok paduan suara Anugerah, di mana beberapa anggotanya adalah orang-orang yang biasa menyanyi di kedai tuak. Itu terjadi 12 tahun lalu, ketika itu baru memulai mencari anggota. Ketika 
datang ke kedai tuak, melihat ada beberapa orang menyanyi sambil ada yang main gitar, lalu ada seseorang yang pegang botol minuman sambil diketuk-ketuk pakai sendok, ternyata bisa menghasilkan satu harmoni yang enak di telinga. Jadi terfikir mengajak orang itu agar ikut nyanyi di gereja dan jadilah kelompok paduan suara itu tetap ada sampai sekarang.

Di sini, tuak dan kedai tuak merupakan bagian dari budaya, dan membentuk pola kebiasaan hidup yang tak mudah lekang dalam diri orang Batak. Meski orang Batak sudah banyak yang merantau ke luar Sumatera, tetapi tuak juga turut dibawa. Kata tuak dikenal baik di Batak, juga di beberapa wilayah seperti Bali, Toraja, Kalimantan, Dayak, dan lain-lain. Di Jawa, bila masa tertentu tuak tidak bisa ditemukan dengan mudah, ada juga dikenal legan, air kelapa yang juga dijadikan orang pengganti tuak, karena rasanya yang punya kemiripan. Mengingat kondisi ini, maka penting sekali membangun kesadaran orang Batak, eksistensi kedai tuak perlu dibaharui kembali, dibangun dan diberi makna baru, agar fungsi dan keberadaan kedai tuak dapat menjadi satu wacana positif dan dapat diefektifkan sebagai satu wadah yang efektif bagi kehidupan orang Batak khususnya kaum bapak.

Batak sendiri bahkan memiliki beberapa mitos, dalam pengertian sastrasastra keagamaan terkait tuak, yang diyakini memiliki sejumlah kebenaran tertentu, dan makna yang terkandung di dalamnya diwariskan turun-temurun. (Schumann 2015). Adapun tuak diperoleh dari bona ni bagot (pohon nira). Sebuah sastra keagamaan Batak memaparkan tentang seorang gadis yang mendapat perlakuan kasar dan tidak manusiawi dari ibu tiri dan saudara- 
saudaranya, setiap hari. Hal itu menjadikan si gadis putus asa dan merasa diri tidak berguna, dan ia pun memohon kepada Tuhan-nya orang Batak, Mulajadi Nabolon, agar kiranya ia dapat menjadi orang yang berguna. Sang gadis pun menengadah dan terus memohon.

Tidak berapa lama, Mulajadi na Bolon mengabulkan permohonan si gadis, ia pun berubah menjadi bona ni bagot (pohon nira). Belakangan, dari pohon nira, beberapa manfaat pohon itu pun mendatangkan kebaikan bagi manusia, seperti: batangnya menghasilkan air, yang disebut tuak (nira). Awalnya, tuak hanya merupakan minuman yang mudah ditemukan di kampung-kampung di mana orang Batak tinggal. Tuak pun biasa diminum orang Batak tak jauh dari pohon nira di mana ia tumbuh. Belakangan ini, oleh karena peminat dan penikmat tuak tidak hanya orang-orang yang tinggal di kampung, urbanisasi orang Batak dari desa ke kota, juga mengikut sertakan tuak. Orang-orang yang bekerja sebagai paragat (penyadap) menjual tuak tersebut ke penadah atau pakter tuak (kedai tuak), dan orang pun berdatangan ke tempat itu. Jadilah tempat itu pakter tuak.

Faktanya, dalam masyarakat Batak, tuak dan juga kedai penjual tuak sangat diminati karena dianggap memiliki beberapa fungsi seperti: fungsi budaya, sosial-ekonomi, pendidikan, pengobatan, dan lain-lain. Dalam setiap ritual budaya Batak selalu ada tuak yang secara khusus dipersiapkan oleh tuan rumah yang mengadakan ritual, untuk disajikan kepada para tamu. Para tamu juga akan merasa senang dan dihormati, bila kepada mereka disajikan tuak di hadapannya.

Dalam situasi seperti itu, tuak menjadi istimewa. Bagi tuan rumah yang memiliki pendapatan cukup, dapat saja disajikan minuman lain seperti bir hitam, 
atau bir putih. Tetapi tanpa kehadiran tuak, sajian itu tidak sempurna. Pertimbangannya sederhana, karena banyak orang juga lebih suka minum tuak, apalagi secara khusus disajikan tuan rumah, tentu tuak itu memiliki kualitas istimewa, yang tidak mudah ditemukan di tempat lain. Sedangkan bir dapat dibeli di mana saja. Menyajikan tuak kepada para tamu dalam setiap pelaksanaan ritual budaya juga terjadi di daerah lain seperti Toraja, dan mungkin daerah lain juga demikian. (Riskiyani, Jannah, dan Rahman 2016). Juga, tuak paling sering disajikan pada acara Rambu Solo, di mana banyak masyarakat yang menghadiri acara itu, disebut sebagai acara adat tersebar di tanah Toraja. Dan semua orang bebas minum tuak tanpa ada larangan, termasuk oleh perempuan dan anak-anak. (Sukiman, Syarifuddin, dan Willem 2019).

Dalam setiap ritual adat Batak, baik sukacita maupun dukacita, selalu ada kesempatan bagi para tamu yang diundang untuk menyampaikan nasehat atau harapan disertai umpasa/umpama (ungkapan). Meski tidak selalu punya arti penting, namun penyebutan umpasa/umpama biasanya untuk memperkuat argumentasi/ menegaskan pendapat yang disampaikan, seperti berikut ini: tuak na tonggi ma tu bagot sibalbalon. Tung paet pe di akka tikki na salpu, ba sai lam tonggi ma tu joloan on (meski sejak dulu hingga sekarang hidup ini terasa pahit, semoga ke depan menjadi indah).

Ini memerlihatkan bahwa penggunaan kata tuak, juga memiliki fungsi pendidikan. Di mana ada sejumlah filosofi tentang hidup orang Batak yang coba diungkapkan lewat kata tuak, seperti: bagot na marhalto ni agatan di robean, horas ma hamu na manganton, tu ganda ma antong di hami na mangalean 
(semoga makanan yang kami sajikan menjadi kekuatan dan kesehatan bagi tuan dan kami beroleh balasannya yang berlimpah di kemudian hari). Penggunaan kata bagot na marhalto di sini menunjuk pada pohon tuak (bagot). Ungkapanungkapan itu bagian dari kebudayaan yang juga mengandung pendidikan filosofi yang penting bagi pembentukan karakter kearifan lokal. (Daniah 2016).

Sebagai tempat berlangsungnya pendidikan informal, melalui pertukaran informasi dan sharing pengalaman dari orang-orang yang datang ke tempat itu. Umumnya sebuah kedai tuak memiliki sejumlah pengunjung tetap, di samping kehadiran orang lain yang hanya sekali-sekali. Biaya yang dibutuhkan dalam pertukaran informasi itu juga relatif kecil. Di beberapa tempat orang, selalu ada orang tertentu yang datang setelah menjelang sore, artinya mereka terlebih dahulu mengerjakan pekerjaan rutinnya, dan menyempatkan datang ke situ untuk sekedar bertegur sapa. Memang ada juga orang-orang tertentu yang tidak punya pekerjaan tetap dan bisa sampai seharian di tempat itu, dan kadang ada juga satu dua orang yang mabuk. Biasanya hal itu karena kurang disiplin.

Di samping itu, tuak juga memiliki beberapa fungsi kesehatan, seperti: tuak biasa diminum sebagai pelepas dahaga dan penambah tenaga dengan pelbagai rasa, baik manis atau pun pahit; tuak berguna bagi kesehatan tubuh juga para ibu yang baru melahirkan, selain penambah tenaga, juga memperlancar dan memperbanyak air susu ibu (ASI) dan juga dapat membersihkan sisa darah kotor saat melahirkan; tuak juga sumber utama pembuatan gula aren yang sangat cocok untuk makanan dan baik untuk kesehatan. Baik, tuak manis pun sangat baik untuk mengatasi kerapuhan tulang (osteoporosis). (Arrazzaq 2019). 
Fungsi sosial-ekonomi terutama dirasakan oleh pemilik kedai, penyadap dan pelayan itu sendiri. Tidak sedikit orang yang menggantungkan penghasilan terhadap usaha kedai tuak. Memang, satu gelas tuak harganya Rp. 3.000.- (tiga ribu rupiah). Namun biasanya kedai tuak tidak hanya menyediakan tuak saja. Karena lajimnya, orang yang minum itu juga butuh tambul, yakni daging atau ikan yang dimasak, dapat juga bersama tempe, tahu, bahkan ada juga yang menyiapkan nasi, mie goreng, teh manis, kopi, dan lain-lain. Kesemuanya itu dibutuhkan para pengunjung, sehingga mereka dapat betah duduk lama sambil juga berbincang satu sama lain.

Kedai tuak memiliki fungsi sosial, sebagai tempat yang penting dan dibutuhkan kaum bapak untuk sekedar tempat bertegur sapa, atau aktualisasi diri. Wadah itu pun digunakan untuk membicarakan berbagai persoalan yang dihadapi di tengah-tengah keluarga, baik menyangkut problem dengan istri atau anak, juga berbagai topik lainnya di seputar pekerjaan, serta pergaulan di tengah-tengah masyarakat adat. Tentu saja kedai tuak pun berfungsi sebagai sarana mengisi waktu dan hiburan sejenak. Biasanya, setelah melakukan aktivitas sehari-hari, banyak orang mengisi waktu sore dengan mendatangi kedai tuak. Kadangkala tujuannya sederhana, hanya untuk punya teman ngobrol, berseloroh, bernyanyi kecil dan berdiskusi, di mana orang-orang dari berbagai tingkatan dan golongan dapat saling menghargai tanpa membedakan status sosial, semuanya merasa setara.

Bagi sebagian orang, kesempatan kecil itu dapat digunakan sebagai 'terapi' untuk mengendorkan ketegangan otot, pikiran bahkan urat syaraf. 
Kadangkala terdengar ungkapan kecil, 'ai, ubat do na tu kode on,' datang ke kedai tuak sama artinya dengan berobat.' Fenomena ini memerlihatkan bahwa kedai tuak dapat berfungsi sebagai tempat yang menginspirasi seseorang dan menemukan gagasan-gagasan besar, yang kemudian tertuang dalam sebuah karya. Komponis besar Batak, Nahum Situmorang, menurut ceritanya sering pergi ke kedai tuak hanya untuk mencari inspirasi dalam menciptakan lagu.

Tentu setiap pemilik kedai juga berharap agar kedai tetap tenang dan nyaman, tidak terganggu oleh pengunjung yang tidak disiplin, agar orang lain tidak jera datang ke kedainya. Oleh karena itu, diskusi yang terbuka dan saling membangun juga perlu dilakukan terhadap pemilik kedai tuak, untuk bersamasama menata kehidupan yang lebih baik, terkait disiplin, jam tutup kedai, jumlah maksimal minuman tuak yang bisa dipesan, dan lain-lain.

Mengingat kehadiran kedai tuak terdapat di setiap tempat di mana biasa gereja berdiri, artinya termasuk wilayah pelayanan gereja, maka gereja tidak bisa menutup mata terhadap kehadiran kedai tuak. Upaya mentransformasi gereja melalui pendidikan budaya dapat dilakukan. Hal itu sekaligus menegaskan hakekat pendidikan sebagai satu proses pengubahan sikap dan perilaku seseorang pribadi/kelompok, dan menjadikannya dewasa.

Hal itu dapat dilakukan dengan memberi makna baru terhadap kebudayaan manusia itu sendiri, dalam pengertian budaya yang melaluinya manusia memperoleh kebutuhannya. (Normina 2018). Dengan demikian, gereja pun dapat merubah kerangka berfikirnya dari memojokkan kehadiran kedai tuak, menjadi 
merangkulnya dan melakukan langkah-langkah persuasif sehingga cara ini dapat diharapkan sebagai satu metode baru dalam rangka pemberitaan Injil.

\section{KESIMPULAN}

Gereja harus senantiasa memerlihatkan eksistensi, tugas dan fungsinya sesuai dengan panggilan gereja itu sendiri, dalam rangka membangun jemaat dalam keseluruhan pelayanan gereja, dengan bercermin dari cara Yesus yang memerlihatkan keberpihakan yang jelas kepada orang-orang kecil, miskin dan tertindas, sebab untuk itulah Yesus datang ke dunia ini (Mat. 25:31-46; Mrk. 14:7; Luk. 5:12-16).

Kenyataan minimnya kehadiran kaum bapak di tengah-tengah gereja mendorong gereja untuk sesegera mungkin memikirkan ulang metode penginjilannya, terutama mengingat tahun 2020 HKBP sedang menapaki "Tahun Zending HKBP," yang menegaskan gereja harus hadir untuk memerbaharui metode penginjilan yang berakar pada karya Tuhan Yesus. (Lumbantobing 2018). Hal itu dapat dimulai sekali dengan melakukan perubahan di dalam gereja itu sendiri, menghadirkan rasa nyaman dalam kehidupan bergereja, menemukan strategi-strategi, kebijakan dan program-program tertentu yang memungkinkan keterlibatan kaum bapak lebih banyak dalam keseluruhan pelayanan gereja.

Pendekatan budaya cukup efektif untuk 'merebut' kembali hati kaum bapak supaya mereka kembali tertarik untuk datang ke gereja. Dengan cara mengembangkan komunikasi verbal dan bahasa tubuh yang menarik. Sikap yang kurang ramah dan terkesan mendikte tentu kurang tepat, terutama bila hal itu 
BONAFIDE: Jurnal Teologi dan Pendidikan Kristen

www.jurnal.sttissiau.ac.id/Volume 1/Nomor 1/Juni 2020/hal. 123-143

dilakukan dalam konteks gereja. Selanjutnya, gereja dapat mulai mengorganisir kedai-kedai tuak yang ada, dan bekerja sama untuk membangun satu aturan untuk menegakkan disiplin bagi setiap pengunjung, juga kemungkinan bila gereja pun dapat membuka ruang diskusi di tempat itu. Tentu komunikasi yang baik dan efektif hanya mungkin terjalin, bila para pelayan sungguh-sungguh untuk membaharui dirinya sebagai pelayan dan menampilkan dirinya sebagai seorang teladan yang peduli atas kehidupan jemaat. Semuanya berguna bagi pembangunan tubuh Kristus.

\section{DAFTAR PUSTAKA}

Afiyanti, Yati. 2008. "Focus Group Discussion (Kelompok Diskusi Terfokus)." Jurnal Keperawatan Indonesia 12 (1). https://doi.org/10.7454/jki.v12i1.201.

Arrazzaq, Muh. 2019. Efektifitas Tuak Manis Sebagai Minuman Sumber Energi Terhadap Daya Tahan Kardiovaskuler Pada Atlet Sepak Bola Sewo Putra FC Kabupaten Soppeng.

Artana, Ketut. 2015. "DISKUSI KELOMPOK TERFOKUS UNTUK MENINGKATKAN KEMAMPUAN GURU EKONOMI DALAM MENYUSUN RENCANA PELAKSANAAN PEMBELAJARAN SESUAI KURIKULUM 2013 DI SMA NEGERI KABUPATEN BULELENG." Daiwi Widya 2 (1). https://doi.org/10.37637/dw.v2i1.132.

Borrong, Robert P. 2019. "KEPEMIMPINAN DALAM GEREJA SEBAGAI PELAYANAN." Voice of Wesley: Jurnal Ilmiah Musik dan Agama 2 (2). https://doi.org/10.36972/jvow.v2i2.29.

Daniah. 2016. "Kearifan Lokal (Local Wisdom) Sebagai Basis Pendidikan Karakter." Pioner - Jurnal Pendidikan 5 (2): 1-14.

Durkhaim, Emile. 1957. The Elementary of the Religious Life. London: George Allen \& Unwin LTD.

Holland, Joe, dan Peter Henriot. 2013. Analisis Sosial dan Releksi Teologis. Yogyakarta: Kanisius.

Lumbantobing, D. 2018. Tumbuh Lokal berbuah Universal. Jakarta: BPK Gunung 
BONAFIDE: Jurnal Teologi dan Pendidikan Kristen

www.jurnal.sttissiau.ac.id/Volume 1/Nomor 1/Juni 2020/hal. 123-143

Mulia.

Ndelo, Yoakim R. 2013. “MEMBIARKAN DIRI DIPIMPIN OLEH ROH' Pengantar Studi Literer Atas Surat Paulus Kepada Jemaat Di Roma (8,127)." Jurnal Teologi 2 (1): 39-48. https://doi.org/10.24071/jt.v2i1.434.

Normina, Normina. 2018. "PENDIDIKAN DALAM KEBUDAYAAN." ITTIHAD 15 (28): 17-28. https://doi.org/10.18592/ITTIHAD.V15I28.1930.

Riskiyani, Shanti, Miftahul Jannah, dan Arsyad Rahman. 2016. “ASPEK SOSIAL BUDAYA PADA KONSUMSI MINUMAN BERALKOHOL (TUAK) DI KABUPATEN TORAJA UTARA." Media Kesehatan Masyarakat Indonesia 11 (2): 76-85. https://doi.org/10.30597/MKMI.V11I2.520.

Schumann, Olaf Herbert. 2015. Pendekatan pada Ilmu Agama-Agama. Jakarta: BPK Gunung Mulia.

Siagian, Riris Johanna. 2019. Agama, Spiritualitas Kepemimpinan, Gereja dan Masyarakat. Pematangsiantar: Lembaga Bina Warga HBP dan Sekolah Pendeta HKBP.

- 2020. "The Understanding of Religion Related to Motivation and Attitude of Religion." In Proceedings of the 1st International Conference on Education, Society, Economy, Humanity and Environment (ICESHE 2019), 154-57. Atlantis Press. https://doi.org/10.2991/assehr.k.200311.030.

Sukiman, Imran, Syarifuddin, dan Ilham Willem. 2019. “ANALISIS FAKTORFAKTOR KONSUMSI MINUMAN KERAS (TUAK PAHIT) PADA REMAJA DI DESA BUNTU TABANG KECAMATAN GANDASIL KABUPATEN TANA TORAJA." Jurnal Ilmiah Manusia Dan Kesehatan 2 (3): 343-53. https://doi.org/10.31850/makes.v2i3.177.

Wulanata, Imanuel Adhitya. 2018. "Peran dan Karya Roh Kudus serta Implikasinya terhadap Pengembangan Pribadi dan Kualitas Pengajaran Guru Kristen [Roles and Work of the Holy Spirit and the Implications for the Personal Development and Teaching Quality of Christian Teachers]." Polyglot: Jurnal Ilmiah 14 (1): 19. https://doi.org/10.19166/pji.v14i1.326. 